\title{
Development of two sequence-specific PCR markers linked to the le gene that reduces pod shattering in narrow-leafed Lupin (Lupinus angustifolius L.)
}

\author{
Jeffrey G. Boersma ${ }^{1,2}$, Bevan J. Buirchell ${ }^{1}$, Krishnapillai Sivasithamparam ${ }^{2}$ and Huaan Yang ${ }^{1}$ \\ ${ }^{1}$ Department of Agriculture and Food, Western Australia, South Perth, Australia. \\ ${ }^{2}$ School of Earth and Geographical Sciences, The University of Western Australia, Nedlands, Australia.
}

\begin{abstract}
Wild types of narrow-leaf lupin (Lupinus angustifolius L.) have seed pods that shatter upon maturity, leading to the loss of their seeds before or during the harvest process. Two recessive genes have been incorporated into domesticated cultivars of this species to maximize harvest-ability of the produce. One of these genes is called lentus (le). Two microsatellite - anchored fragment length polymorphism (MFLP) candidate markers were identified as closely linked to the le gene in a recombinant inbred line (RIL) population derived from a domesticated $\mathrm{x}$ wild type cross. The candidate MFLP markers were isolated from the gel, re-amplified by PCR, cloned and sequenced. The MFLP polymorphisms were converted into sequence-specific PCR-based markers. Linkage analysis by MapManager indicated that one of the markers, LeM1, was 2.6 centiMorgans (cM) and the other, LeM2, was $1.3 \mathrm{cM}$ from the gene, with both being on the same side. The correlation between the marker genotype and the plant phenotype for the le gene is $95 \%$ for the Australian cultivars, and approximately $36 \%$ on wild types tested. These markers may be useful in marker assisted selection for the le gene when introgressing wild material into lupin breeding programs.
\end{abstract}

Key words: pod shattering, Lupin, MFLP, molecular marker, marker assisted selection.

Received: October 5, 2006; Accepted: March 1, 2007.

\section{Introduction}

An essential characteristic of a modern grain crop is the ability to retain its seeds long enough to allow mechanical harvesting at full maturity. In the genus Lupinus, this characteristic has long been present in two species Lupinus albus L., an old crop species of the Mediterranean region, and L. mutabilis (sweet) which has been cultivated in the Peruvian Andes for over 2000 years (Gladstones, 1967).

Narrow-leaf lupin (Lupinus angustifolius L.) is the most widely cultivated grain legume crop in Australia. Originally introduced into Western Australia (W.A.) towards the end of the $19^{\text {th }}$ century (Gladstones, 1994) as a green manure crop, these plants were essentially wild. Wild types of $L$. angustifolius have seed pods that shatter upon maturity, making harvesting very difficult. Research aimed at finding plants with non-shattering pods was reported to have begun in Germany in 1929 (Hanelt, 1960). They were successful in selecting a strain that had a reduced pod shatter (von Sengbusch and Zimmermann, 1937) apparently related to a large reduction in the thick-

Send correspondence to J.G. Boersma. Department of Agriculture and Food, 3 Baron-Hay Court, South Perth, WA 6151, Australia. E-mail: jboersma@agric.wa.gov.au. ness of the pod wall (Atebekova, 1958). Domestication of this species in W.A. began in 1960 with the discovery of two natural mutant (recessive) genes, lentus and tardus for reduced pod-shattering (Gladstone, 1967) and, in 1961 a gene for nil-vernalisation requirement and early flowering (Gladstones, 1969).

One of the genes for reduced pod-shatter, known as tardus (ta), affects the sclerenchyma strips of the dorsal and ventral pod seams, fusing the two halves to such an extent that separation of the two halves is greatly impeded. It was considered analogous to a gene previously found in $L$. luteus. The second gene lentus (le) modified the orientation of the sclerified endocarp of the pod, resulting in a reduction of torsional forces upon drying, and hence reduced pod shatter. This gene was also associated with a reduction in the thickness of the pod wall, but not to the extent of the previously found strain of von Sengbusch and Zimmerman (1937), leading to the conclusion that the controlling genes were not the same (Gladstones, 1967). This modification was associated with a change in internal pod pigmentation that gave the immature pods a purplish tinge and the inside surface of mature pods a bright yellowish-brown color (Gladstones, 1967). In addition, this trait is also associated with development of a reddish pigmentation within the stem of plants older than two months. The first Australian 
cultivar to carry both these genes was Uniharvest, released in 1971. Apart from Fest (released 1973) all Australian and many European cultivars released since then carry both of these genes.

Since field based selection for the $l e$ gene requires that the $F_{2}$ progeny be maintained for at least 8 weeks from sowing to ensure that this trait is retained, it would be more efficient to use molecular markers that could be used to evaluate progeny within the first weeks of growth. Recently, two molecular genetic maps have been produced in L. angustifolius on which le has been mapped (Boersma et al., 2005; Nelson et al., 2006). No marker was located within 5 centiMorgans $(\mathrm{cM})$ of the le gene on the map of Nelson et al. (2006). Conversely, several markers on the map of Boersma et al. (2005) were closely linked to the le gene. However, the MFLP markers in the map of Boersma et al. (2005) are not implementable in practical lupin breeding as the multiple bands produced by their primer combinations may cause confusion, makes it impossible to multiplex several markers for high efficiency and, is too tedious and expensive to be implemented in a lupin breeding program for screening large numbers of plants. The aim of this research is to develop simple, sequence-specific PCR based markers linked to the $l e$ gene desirable for marker assisted selection (MAS) in lupin breeding.

\section{Material and Methods}

\section{Plant materials and phenotyping of le gene}

A population of $\mathrm{F}_{8}$ recombinant inbred lines (RILs) of a domestic $\mathrm{x}$ wild type (DxW) cross of L. angustifolius was previously developed by the Department of Agriculture and Food, Western Australia (DAFWA) using as parents lines P27255 (wild) and 83A:476 (domesticated). Part of the resulting RIL population has previously been used to produce linkage maps for L. angustifolius (Boersma et al., 2005; Nelson et al., 2006).

The full population consisting of two parents and 115 RILs, was sown in a screen-house during the winter growing season with 25-30 plants of each RIL grown in 1.5 meter rows. Plants were either rated as LeLe (wild, shattering; pigment absent) or lele (domesticated, reduced shattering; pigment present) based on the method described by Gladstones (1967).

\section{Marker development}

The parents and 89 RILs were previously subject to MFLP tests involving $10 \mathrm{SSR}$-anchor primers each in combination with $16 \mathrm{Mse}$ I-primers (Boersma et al., 2005). Two MFLP markers having the best correlation to the le phenotyping data were selected. DNA fragments from candidate MFLP markers were isolated from MFLP gels, re-amplified by PCR, ligated into plasmids (pGEM-T Easy Vector, Promega) and cloned into E. coli according to the manufacturer's instructions. Plasmid DNA with MFLP fragment in- serts were isolated from E. coli, and sequenced using the BigDye Terminator system (Applied Biosystems). To ensure the accuracy of DNA sequencing, at least five clones of $E$. coli were used to prepare the plasmid DNA containing the inserts, and sequenced separately. A sequence-specific primer was designed near the MseI-end internal to the SSR-MseI fragment. (Yang et al., 2002, 2004; You et al., 2005). Primers were designed so that the annealing temperature was approximately $54{ }^{\circ} \mathrm{C}$ based on calculations using the nearest-neighbor model (http://www.sigmaaldrich. com).

\section{Testing of converted markers}

Testing of the converted markers was achieved by $\mathrm{PCR}$, using the sequence-specific primer in combination with the SSR anchor-primer from which the original MFLP polymorphism was produced (Yang et al., 2001, 2002). Marker DNA fragments were amplified in a $10 \mu \mathrm{L}$ PCR consisting of $1.5 \mu \mathrm{L}$ of the template DNA (approximately $100 \mathrm{ng}$ ), 0.5 unit of Taq polymerase (Fisher Biotec, Perth), 5 pmol of each primers, $67 \mathrm{mM}$ Tris- $\mathrm{HCl}$ (pH 8.8), $2 \mathrm{mM} \mathrm{MgCl} 2,16.6 \mathrm{mM}\left(\mathrm{NH}_{4}\right)_{2} \mathrm{SO}_{4}, 0.45 \%$ Triton X-100, $4 \mu \mathrm{g}$ gelatin, and $0.2 \mathrm{mM}$ dNTPs. The sequence-specific primers were labeled with $\gamma_{-}{ }^{33} \mathrm{P}$ based on a previously reported method (Yang et al., 2001, 2002, 2004). PCR was performed on a thermocycler (Hybaid DNA Express) with each cycle comprising 30s at $94{ }^{\circ} \mathrm{C}$, $30 \mathrm{~s}$ at the annealing temperature (see below), and $1 \mathrm{~min}$ at $72^{\circ} \mathrm{C}$. The annealing temperature of the first cycle was $60{ }^{\circ} \mathrm{C}$, and decreased $0.7^{\circ} \mathrm{C}$ in each subsequent cycle until the temperature reached $54{ }^{\circ} \mathrm{C}$. The final 25 cycles used an annealing temperature of $54{ }^{\circ} \mathrm{C}$. The selective PCR products were separated on a $5 \%$ polyacrylamide denaturing sequencing gel ( $7 \mathrm{M}$ urea) using a $38 \times 50 \mathrm{~cm}$ (0.4 $\mathrm{mm}$ in thickness) Sequi-Gen GT sequencing cell (Bio-Rad). After electrophoresis at $55 \mathrm{~W}$ for about $3 \mathrm{~h}$, the gel was dried on a gel drier (Model 583, Bio-Rad). Marker bands were detected by autoradiography (Yang et al., 2002; You et al., 2004) with overnight exposure of the X-ray film to the dried gel.

\section{Confirmation of linkage}

The two converted sequence - specific markers were tested on all $115 \mathrm{~F}_{8}$ RILs of the population derived from the DxW cross. The marker score data and le phenotype data of the $115 \mathrm{~F}_{8}$ RILs were merged and analyzed using MapManager (Manly et al., 2001) to determine the genetic linkage between the markers and the le gene.

Further testing of the markers was carried out on all 23 Australian historical and current cultivars and on 36 landrace accessions from the Australian Lupin Collection, to examine correlation of their phenotype with the le markers' genotypes. Landrace accessions were selected on the basis of their geographic origins. 


\section{Results}

\section{Phenotyping of le gene}

Phenotyping on the individual plants from each of the 115 RILs revealed that 55 RIL lines were homozygous for le (reduced shatter), and 60 lines were homozygous for $L e$ (shattering). The segregation of RILs with the lele genotype to plants with the LeLe genotype fits the expected 1:1 ratio $\left(\chi^{2}=0.217, P=0.641\right)$ for a single gene.

\section{DNA sequencing of candidate MFLP markers}

Among the markers originated from 153 sets of MFLPs during a mapping study (Boersma et al., 2005), two dominant markers designated as DAWA323.150 and DAWA468.290 were identified as candidate markers for development as sequence-specific markers tagging the le gene.

Marker DAWA323.150 mapped as1.2 $\mathrm{cM}$ from the le gene in the map based on the 89 RILs (Boersma et al., 2005), was present in RILs with lele genotype, but was absent in RILs with LeLe genotype (Figure 1). DNA sequencing found that MFLP marker DAWA323.150 is a $157 \mathrm{bp}$ fragment including the sequence of SSR-anchor primer MF51 (5-GGGAACAACAACAAC-3') and the primer MseI-CGA (5-GATGAGTCCTGAGTAACGA-3') (Table 1).

Marker DAWA468.290 was also present in plants with lele genotype but absent in plants with LeLe genotype (Figure 2). This marker had not been shown in the map (Boersma et al., 2005) as it was also calculated to be $1.2 \mathrm{cM}$ from the le gene, and therefore co-segregated with marker DAW323.150. DNA sequencing revealed that marker DAWA468.290 is a $284 \mathrm{bp}$ fragment including the anchor primer sequence MF42 (3- GTCTAACAACAACAACA AC-5') and the sequence of primer MseI-CCA (5'-GATGA GTCCTGAGTAACCA-3') (Table 2).

Marker LeM1: Based on the DNA sequence of MFLP marker DAWA323.150, a sequence-specific primer LeMS1 (3'-TTAACGAACCTACCATTTG-5') was designed near the MseI end of the original MFLP marker (Table 1). The dominant MFLP marker was successfully converted into a dominant simple PCR based marker by

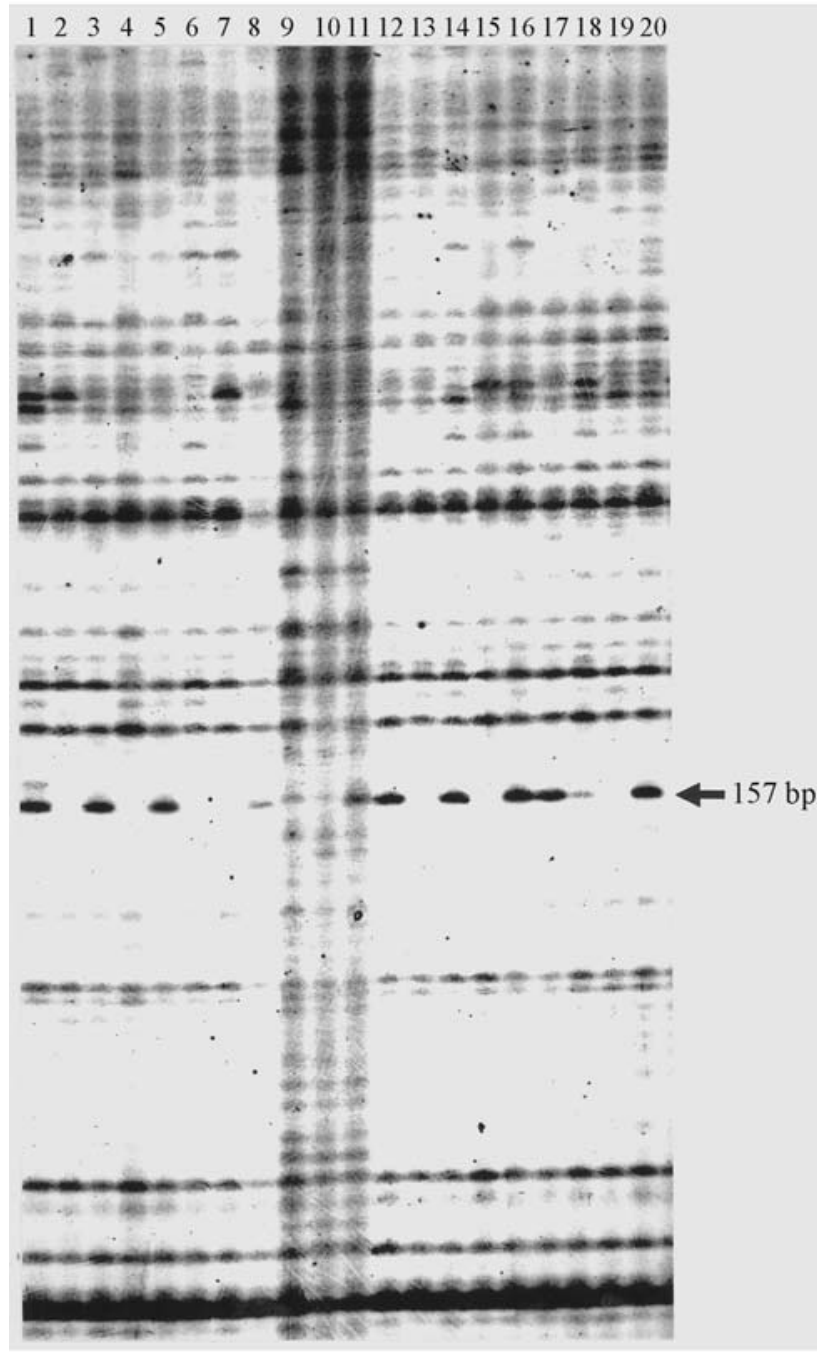

Figure 1 - MFLP fingerprinting on 20 RILs derived from a domesticated $\mathrm{x}$ wild cross in Lupinus angustifolius generated by SSR-anchor primer MF51 in combination with primer MseI-CGA. Eight RILs having the LeLe genotype are (DxW) 58 (Lane 2), 60 (Lane 4), 65 (Lane 6), 66 (Lane 7), 70 (Lane 9), 73 (Lane 10), 77 (Lane 13), and, 85 (Lane 19). Eleven RILs: (DxW) 57 (Lane 1), 59 (Lane 3), 64 (Lane 5), 69 (Lane 8), 74 (Lane 11), 76 (Lane 12), 78 (Lane 14), 82 (Lane 16), 83 (Lane 17), 84 (Lane 18), and 86 (Lane 20) have the genotype lele. Note that all of the 20 plants except one (RIL 80, Lane 15) showed correct correlation between the le phenotype and the marker genotype. Arrow indicates the candidate MFLP marker linked to the le allele at $157 \mathrm{bp}$.

Table 1 - DNA sequence of the MFLP marker DAWA323.150 showing primers giving rise to sequence-specific marker LeM1.

\begin{tabular}{ll}
\hline Position & Sequence \\
\hline 1 & GATGAGTCCT GA $\underline{\text { GTAACGA }}{ }^{1} \underline{\text { A }} \underline{\text { CCTACCATTT G }^{2} \text { CCTAAACAA TATATTGTTT }}$ \\
51 & ACTGGTTGTT GTTGTTGTTC TTCTTCTTCT TCCTCTTCTT CCTCTTCTTC \\
101 & TTCTTCTTCT TACCATTTGC CTAAACAATA TATTGTTTAC TG $\underline{\text { TTTGTTGT }}$ \\
151 & $\underline{\text { TGTTCCC }}^{3}$ \\
\hline
\end{tabular}

${ }^{1}$ Primer $M s e$ I-CGA (5'-GATGAGTCCTGAGTAACGA-3') is in italic.

${ }^{2}$ Sequence-specific primer LeBMS1 (5'-TTAACGAACCTACCATTTG-3').

Note: The first $4 \mathrm{bp}$ in primer LeBMS1 corresponds with the recognition site of MseI (T/TAA), while the first nucleotide (T) was replaced by G when the MseI-adaptor was ligated onto the restriction fragments in MFLP (Yang et al. 2001).

${ }^{3}$ Annealing site of SSR-anchor primer MF51 (3'-GGGAACAACAACAAC-5'). 
using the sequence-specific primer LeBMS1 in combination with SSR-anchor primer MF51. $\mathrm{F}_{8}$ RILs with the genotype lele developed the $126 \mathrm{bp}$ marker band, while plants with genotype LeLe did not develop this band (Figure 3). We designated this sequence-specific dominant marker linked to the le gene as LeM1.

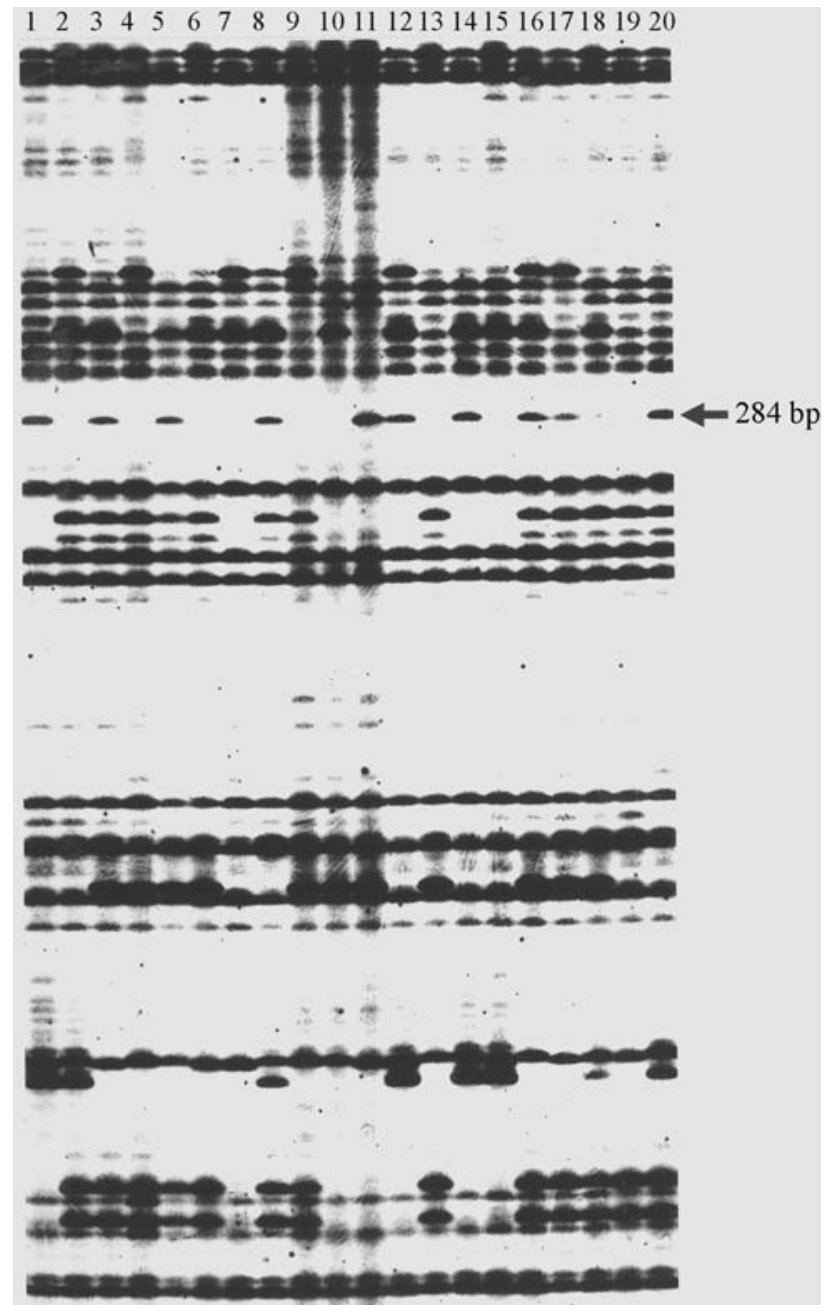

Figure 2 - MFLP fingerprinting on 20 RILs in Lupinus angustifolius generated by SSR-anchor primer MF42 in combination with primer MseI-CCA. RILs portrayed in this figure are the same as in Figure 1. Arrow indicates the candidate MFLP marker linked to the le allele at $284 \mathrm{bp}$.
Marker LeM2: A sequence-specific primer LeMS2 (3'-AGAAAAAGATGAATGCACG-5') was designed near the MseI end based on the sequence of MFLP marker DAWA468.290 (Table 2). The marker was successfully converted into a simple PCR based marker by using primer LeMS2 in combination with SSR-anchor primer MF42. Plants with genotype lele produced a 204 bp marker band, but the marker fragment is absent in plants with LeLe genotype (Figure 4). We designated this marker as LeM2.

\section{Confirmation of linkage}

Markers LeM1 and LeM2 were tested on the parents and 115 RILs of the DxW population. Marker results and RIL genotypes showed imperfect correlation, with LeM1 having six differences and, LeM2 having three differences between the marker result and RIL genotypes. The three RILs which showed inconsistence between phenotype and marker genotype of LeM2 also showed the inconsistency with LeM1. Map distances were calculated by MapManager (Manly et al., 2001) to be $1.3 \mathrm{cM}$ (LeM2) and $2.6 \mathrm{cM}$ (LeM1) from the gene (Figure 5).

Among the 23 Australian cultivars, only the first released cultivar Uniwhite, carries the shattering alleles LeLe, and all the other 22 cultivars have the reduced-shattering genotype lele. The 22 cultivars having the lele genotype were correctly scored by the markers. However, the marker genotype and Le phenotype of Uniwhite did not match (Table 3).

The Australian lupin collection holds many accessions of wild and landrace L. angustifolius collected or received from a range of locations. Most of these accessions have been rated as either 'shedding' (shattering; no $l e$ or $t a$ ), 'reduced shedding' (carrying at least one gene reducing pod shatter) or 'non-shedding' (presumably carrying at least 2 genes for the reduction of pod shatter).

Of the 36 landraces, marker LeM1 designated only six accessions as Le ('shedding' (shattering)) and LeM2 designated seven as $L e$, despite all but one of them having previously been rated as $L e$ ('shedding', Australian Lupin Collection database, 2005). Only one of the accessions was designated as $L e$ by both markers. Similarly, both markers

Table 2 - DNA sequence of the MFLP marker DAWA468.290 showing primers giving rise to sequence-specific markers LeM2.

\begin{tabular}{|c|c|}
\hline Position & Sequence \\
\hline 1 & GATGAGTCCT GAGTAACCA $^{1}$ C TCATAGTTTA TAAACTCTCC AATTGTTTGT \\
\hline 51 & TATTCTCATG TATTATATCC TATCTCACAA $\underline{\text { AGAAAAAGAT GAATGCACG }}^{2} \mathrm{~A}$ \\
\hline 101 & GTTTTTTAGT ACAAATTTCA TCCTACACTG AATCTGTTGA AATTGAAATG \\
\hline 151 & AATATCACAA AACATTTTGC TGCAGTGTCG GTCTTGCTTT ACCATTCGTG \\
\hline 201 & GTGGCAACAC TTACACGTCA AGCAAAGTCA TTGATGGATG CCCCACCTAC \\
\hline 251 & TGTGATAAAA GCTTGGTTGT TGTTGTTGTT AGAC ${ }^{3}$ \\
\hline
\end{tabular}

${ }^{1}$ Primer $M s e I-C C A$ (5'-GATGAGTCCTGAGTAACCA-3').

${ }^{2}$ Sequence-specific primer LeMS2 (5'-AGAAAAAGATGAATGCACG-3').

${ }^{3}$ Annealing site of primer MF42 (3'-GTCTAACAACAACAACAAC-5'). 


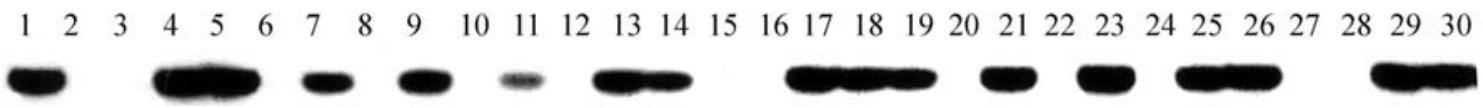

Figure 3 - Screening molecular marker LeM1 on the parents and $28 \mathrm{~F}_{8}$ derived RILs of Lupinus angustifolius using PCR with sequence-specific primer LeMS1 (5'-TTAACGAACCTACCATTTG-3') and SSR anchor primer MF51. Lines with the lele genotype which developed a 126 bp band include the domesticated parent plant 83A:476 (Lane 1) and 21 RILs: (DxW) 67 (Lane 4), 69 (Lane 5), 71 (Lane 7), 74 (Lane 9), 76 (Lane 11 ), 78 (Lane 13), 79 (Lane 14), 82 (Lane 17), 83 (Lane 18), 84 (Lane 19), 86 (Lane 21), 90 (Lane 23), 93 (Lane 25), 94 (Lane 26), 97 (Lane 29) 98 (Lane 30). Plants with the LeLe genotype which did not produce the marker band are the wild type parent P27253 (Lane 2) and 11 RILs: 66 (Lane 3), 70 (Lane 6), 73 (Lane 8), 75 (Lane 10), 77 (Lane 12), 81 (Lane 16), 85 (Lane 20), 89 (Lane 22), 92 (Lane 24), 95 (Lane 27), 96 (Lane 28). RIL DxW 80 (Lane 15) also produced no band despite carrying the lele allele.

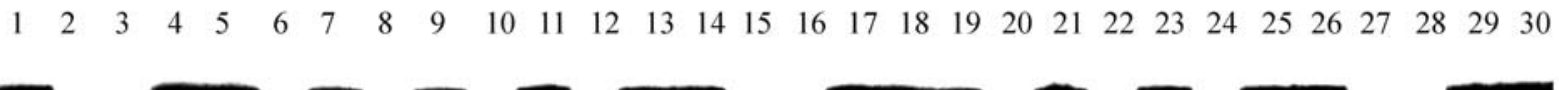

Figure 4 - Screening molecular marker LeM2 on the parents and $28 \mathrm{~F}_{8}$ derived RILs of Lupinus angustifolius using PCR with sequence-specific primer LeMS2 (3'-GAAAAAGATGAATGCACG-5') and SSR anchor primer MF42. The length of the band fragment produced here is $204 \mathrm{bp}$. RILs portrayed in this figure are the same as in Figure 3.

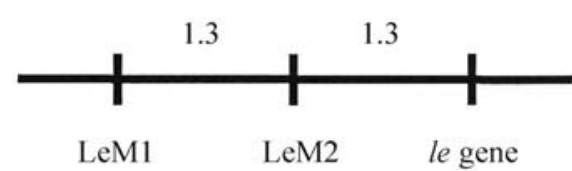

Figure 5 - Genetic linkage of the two molecular markers LeM1 and LeM2 and the reduced-pod-shatter gene lentus (le) of Lupinus angustifolius, as analyzed by MapManager. Distances between adjacent points given in centiMorgans (on the left side) between adjacent points on the linkage map are non-cumulative.

designated as $l e$ the one accession listed as 'non-shedding', received from Belarus (Table 4). Accessions correctly designated as $L e$ or $l e$ were collected (or received) from eight countries including Belarus, France, Greece, Italy, Morocco, Portugal, Spain, Syria. Accessions from the other eight source countries including Cyprus, Chile, Germany, India, Israel, Turkey, USA and the USSR were incorrectly genotyped by the two markers. In total, 13 out of $36(36 \%)$ land-race accessions showed a positive correlation between marker score and pod-shatter genotypes for one or both markers.

\section{Discussion}

We have successfully developed two sequence-specific PCR markers linked to the Le gene in L. angustifolius in this study. Both markers are simple PCR based, are costeffective, and could be used for MAS in lupin breeding. Previously Boersma et al., (2005) had mapped marker DAWA323.150 from which LeM1 was derived as being only $1.2 \mathrm{cM}$ from the gene based on 89 RILs. This distance has now been re-calculated as being $2.6 \mathrm{cM}$ from the gene on the basis of a population of 115 RILs, including the 89 RILs previously used by them. LeM2 which had not previously been placed on the map has been positioned mid-way between the $L e$ gene and LeM1 at $1.3 \mathrm{cM}$. The genetic distance between the marker and the gene determines the ac-
Table 3 - Correlation of marker score and Le phenotype of 23 Australian cultivars of Lupinus angustifolius.

\begin{tabular}{|c|c|c|c|c|}
\hline Cultivars & $\begin{array}{l}\text { Year of } \\
\text { release }\end{array}$ & $\begin{array}{c}\text { Lentus } \\
\text { phenotype }\end{array}$ & $\begin{array}{l}\text { Presence of } \\
\text { LeM1 } \\
\text { marker band }\end{array}$ & $\begin{array}{c}\text { Presence of } \\
\text { LeM2 } \\
\text { marker band }\end{array}$ \\
\hline Uniwhite & 1967 & LeLe & + & + \\
\hline Uniharvest & 1971 & lele & + & + \\
\hline Unicrop & 1973 & lele & + & + \\
\hline Marri & 1976 & lele & + & + \\
\hline Illyarrie & 1979 & lele & + & + \\
\hline Yandee & 1980 & lele & + & + \\
\hline Chittick & 1982 & lele & + & + \\
\hline Danja & 1986 & lele & + & + \\
\hline Geebung & 1987 & lele & + & + \\
\hline Gungurru & 1988 & lele & + & + \\
\hline Yorrel & 1989 & lele & + & + \\
\hline Warrah & 1989 & lele & + & + \\
\hline Merrit & 1991 & lele & + & + \\
\hline Myallie & 1995 & lele & + & + \\
\hline Kalya & 1996 & lele & + & + \\
\hline Wonga & 1996 & lele & + & + \\
\hline Belara & 1997 & lele & + & + \\
\hline Tallerack & 1997 & lele & + & + \\
\hline Tanjil & 1998 & lele & + & + \\
\hline Moonah & 1998 & lele & + & + \\
\hline Quilinock & 1999 & lele & + & + \\
\hline Jindalee & 2000 & lele & + & + \\
\hline Mandelup & 2004 & lele & + & + \\
\hline
\end{tabular}

Note: Both LeM1 and LeM2 are dominant markers, where the marker band is linked to the le allele. The one cultivar incorrectly identified by the markers, Uniwhite, is presented in bold.

$+=$ band present.

- = band absent. 
Table 4 - Correlation of marker score and Le phenotype of 36 Wild and Landrace accessions of $L$. angustifolius from the Western Australian Lupin Collection.

\begin{tabular}{|c|c|c|c|c|}
\hline $\begin{array}{l}\text { Landrace } \\
\text { (Perth n.) }\end{array}$ & Origin & $\begin{array}{c}\text { Lentus } \\
\text { phenotype }\end{array}$ & $\begin{array}{l}\text { Presence of } \\
\text { LeM1 } \\
\text { marker band }\end{array}$ & $\begin{array}{l}\text { Presence of } \\
\text { LeM2 } \\
\text { marker band }\end{array}$ \\
\hline P20650 & Portugal & LeLe & + & + \\
\hline P20653 & Portugal & LeLe & + & + \\
\hline P20711 & Italy & LeLe & + & + \\
\hline P20712 & Italy & LeLe & + & - \\
\hline P20714 & Italy & LeLe & + & + \\
\hline P20724 & Italy & LeLe & + & + \\
\hline P20729 & Russia & LeLe & + & + \\
\hline P20730 & Russia & LeLe & + & + \\
\hline P20733 & Germany & LeLe & + & + \\
\hline P20736 & Israel & LeLe & + & + \\
\hline P21517 & Israel & LeLe & + & + \\
\hline P21624 & Turkey & LeLe & + & + \\
\hline P21625 & Syria & LeLe & + & + \\
\hline P22609 & Turkey & LeLe & + & + \\
\hline P22665 & Spain & LeLe & - & + \\
\hline P22666 & Spain & LeLe & - & + \\
\hline P22669 & Spain & LeLe & + & + \\
\hline P22820 & Portugal & LeLe & + & - \\
\hline P22829 & Portugal & LeLe & + & - \\
\hline P23051 & France & LeLe & + & - \\
\hline P24025 & India & LeLe & + & + \\
\hline P26042 & USA & LeLe & + & + \\
\hline P26045 & Greece & LeLe & + & + \\
\hline P26235 & Spain & LeLe & + & - \\
\hline P26263 & Portugal & LeLe & + & - \\
\hline P26307 & Spain & LeLe & + & + \\
\hline P26308 & Spain & LeLe & + & + \\
\hline P26436 & Greece & LeLe & + & + \\
\hline P26465 & Greece & LeLe & - & + \\
\hline P26652 & Italy & LeLe & + & + \\
\hline P26675 & Cyprus & LeLe & + & + \\
\hline P27055 & Belarus & lele & + & + \\
\hline P27253 & Morocco & LeLe & - & - \\
\hline P27434 & Syria & LeLe & - & + \\
\hline P27968 & Greece & LeLe & - & + \\
\hline P28003 & Chile & LeLe & + & + \\
\hline
\end{tabular}

Note: Both LeM1 and LeM2 are dominant markers, where presence of the marker band is linked to the le allele. Accessions for which the Le phenotype correlates with either or both of the two markers are presented in bold. $+=$ band present.

- = band absent.

curacy of marker assisted selection when the marker is used in the breeding program. Since markers LeM1 and LeM2 are both on the same side of the le gene, and LeM2 is closer to the gene than LeM1, it would be appropriate to use marker LeM2 in MAS if both markers are applicable.
For MAS, it would be ideal to develop so-called 'perfect Markers' where the DNA fragments of the markers are actually on the gene of interest, in which case the linkage between the markers and the gene is almost unbreakable (Ellis et al., 2002). However, perfect markers are very difficult to develop. Most of the molecular markers being implemented in practical plant breeding programs are 'imperfect' where certain genetic distances exist between the markers and the gene of interest in the chromosomes (Staub and Serquen, 1996; Gupta et al., 1999). The two markers linked to the Le gene in lupin reported in this paper, are like-wise imperfect. Over long periods of time and in the crossing in plant breeding programs, genetic recombination may occur between the marker locus and the gene locus, and consequently plants not having the target gene may carry the marker DNA sequence, and vice-versa (Sharp et al., 2001, You et al., 2005). In MAS, a molecular marker can be used to screen the progeny from a cross only if the marker is polymorphic among the parents so that the desirable allele can be distinguished from the undesirable ones (Eagles et al., 2001). Fortunately, all the modern Australian cultivars having the lele genotype show the target bands for markers LeM1 and LeM2. However, testing of these markers on land-races that were fully shattering (having the LeLe,TaTa genotype) resulted in only 13 of the 36 landrace accessions correlating the marker bands with genotype. Eleven of those 13 accessions were correctly identified by either one or the other of the two markers, indicative of the degree of crossing over that has occurred between the marker and the le gene in the wild, even though it only occurs at an estimated $1.3-2.6 \%$ of the time in any given cross. The results suggest that these markers may be of use in MAS to screen the progeny of approximately one third of wild accessions when they are crossed with modern Australian cultivars. This study although not exhaustive, also suggests that these markers would be more likely useful when testing progeny of seed material originating from Greece, Morocco (source of DxW parent P27255), Portugal, Spain and Syria, although seed received from other sources including collections (e.g. France, Belarus) should not be ruled out.

When markers LeM1 and LeM2 are used to screen the $\mathrm{F}_{2}$ progenies from $\mathrm{DxW}$ crosses, they enable breeders to eliminate the approximately $25 \%$ of plants which are homozygous for the LeLe allele. However, since both markers are dominant, they cannot differentiate homozygous lele $\mathrm{F}_{2}$ plants from the heterozygous Lele plants. Therefore, further selection for the lele genotype may be necessary in later generations of the breeding cycle.

\section{References}

Atebekova AI (1958) The dehiscence of the pods in the genus Lupinus (Tourn.) L. Bull Moscow Soc Nat Res 63:89.

Boersma JG, Pallotta M, Li C, Buirchell BJ, Sivasithamparam K and Yang H (2005) Construction of a genetic linkage map 
using MFLP and identification of molecular markers linked to domestication genes in narrow-leafed lupin (lupinus angustifolius L.). Cell Mol Biol Lett 10:331-344.

Eagles HA, Bariana HS, Ogbonnaya FC, Rebetzke GJ, Hollamby GJ, Henry RJ, Henschke PH and Carter M (2001) Implementation of markers in Australian wheat breeding. Aust $\mathrm{J}$ Agric Res 52:1349-1356.

Ellis MH, Spielmeyer W, Gale KR, Rebetzke GJ and Richards RA (2002) "Perfect" markers for the Rht-B1b and Rht-D1b dwarfing genes in wheat. Theor Appl Genet 105:1038-1042.

Gladstones JS (1967) Selection for economic characters in Lupinus angustifolius and L. digitatus. 1. Non-shattering pods. Aust J Exp Agric and Anim Husb 7:360-366.

Gladstones JS (1969) Selection for economic characters in Lupinus angustifolius and $L$. digitatus. 2. Time of flowering. Aust J Exp Agric Anim Husb 9:213-220.

Gladstones JS (1994) An historical review of lupins in Australia. 1-38. In: Dracup M and Palta J (eds) Proceedings of the First Australian Lupin Technical Symposium. Department of Agriculture, Western Australia, pp 1-38.

Gupta PK, Varshney PK, Sharma PC and Ramesh B (1999) Molecular markers and their applications in wheat breeding. Plant Breeding 118:369-390.

Hanelt P (1960) The Lupins. A Ziemsen, Wittenberg, 104 pp.

Manly KF, Cudmore Jr RH and Meer JM (2001) MapManager QTX, cross-platform software for genetic mapping. Mammalian Gen 12:930-932.

Nelson MN, Phan HTT, Ellwood SR, Moolhuijzen PM, Bellgard M, Hane J, Williams A, O'Lone CE, Fosu-Nyarko J, Scobie M, et al. (2006) The first gene-based map of Lupinus angustifolius L.-Location of domestication genes and conserved synteny with Medicago truncatula. Theor Appl Genet 113:225-238.
Sengbusch von R and Zimmermann K (1937) Die Auffindung der ersten gelben und blauen Lupinen (Lupinus luteus und Lupinus angustifolius) mit nichtplatzenden Hülsen und die damit zusammenhängenden Probleme, insbesondere die der Süsslupinenzüchtung. Züchter 9:57-65.

Sharp PJ, Johnston S, Brown G, McIntosh RA, Pallotta M, Carter M, Bariana HS, Khatkar S, Lagudah ES, Singh RP, et al. (2001) Validation of molecular markers for wheat breeding. Aust J Agric Res 52:1357-1366.

Staub JE and Serquen FC (1996) Genetic markers, map construction, and their application in plant breeding. HortScience 31:729-740.

Yang H, Sweetingham MW, Cowling WA and Smith PMC (2001) DNA fingerprinting based on micro-satellite anchored fragment length polymorphisms, and isolation of sequence-specific PCR markers in lupin (Lupinus angustifolius L.). Mol Breed 7:203-209.

Yang H, Shankar M, Buirchell BJ, Sweetingham MW, Caminero $\mathrm{C}$ and Smith PMC (2002) Development of molecular markers using MFLP linked to a gene conferring resistance to Diaporthe toxica in narrow-leafed lupin (Lupinus angustifolius L.). Theor Appl Genet 105:265-270.

Yang H, Boersma JG, You M, Buirchell BJ and Sweetingham MW (2004) Development and implementation of a sequence-specific PCR marker linked to a gene conferring resistance to anthracnose disease in narrow-leafed lupin (Lupinus angustifolius L.). Mol Breed 14:145-151.

You M, Boersma JG, Buirchell BJ, Sweetingham MW, Siddique KHM and Yang H (2005) A PCR-based molecular marker applicable for marker-assisted selection for anthracnose disease resistance in lupin breeding. Cell Mol Biol Lett 10:123-134.

Associate Editor: Everaldo Gonçalves de Barros 